P-ISSN: 2774-4574; E-ISSN: 2774-4582 TRILOGI, 1(1), Mei-Agustus 2020 (29-41) @2020 Lembaga Penerbitan, Penelitian, dan Pengabdian kepada Masyarakat (LP3M) Universitas Nurul Jadid Paiton Probolinggo DOI: https://doi.org/

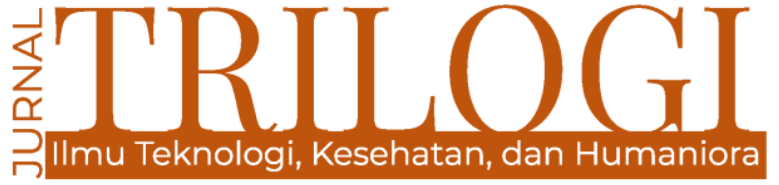

\title{
MENGHADIRKAN “NABI": Antara Hasrat dan Cinta dalam Ritus Shalawat Bersama pada Majelis Syubbanul Muslimin
}

\author{
Akhmad Muzakki \\ UIN Maulana Malik Ibrahim Malang, Indonesia \\ akh.muzakki@uin-malang.ac.id
}

\begin{abstract}
This study seeks to position shalawat activities together as an arena for reproduction and consumption of religious capital through various socio-economic-cultural process. By making Syubbanul Muslimin an object of research, this study used sensory anthropological approach by means of analyzing the world and the actions of our informants and research subjects by walking, working, discussing the results of shooting, eating, and talking to informants. The results of this study showed that through practicing shalawatan, Prophet Muhammad was "presented" and "projected" in accordance with the local interpretation of the Muslim Majelis Syubbanul Muslimin. The event "Shalawat Bersama" is a rite of religion and / or art in Islam based on sufistic piety: shalawat, dhikr (prayer), and barokah (blessing) packed from the desire to love into a desire in the terms of mode of advanced capitalism.
\end{abstract}

Keywords: Syubbanul Muslimin; the presence of the Prophet; desire; love

\begin{abstract}
Abstrak
Studi ini berusaha memosisikan kegiatan shalawat bersama sebagai arena reproduksi dan konsumsi modal religius melalui berbagai modal sosio-ekonomi-kultural. Dengan menjadikan Syubbanul Muslimin sebagai objek penelitian, pendekatan yang digunakan dalam studi ini adalah antropologi inderawi dengan cara-cara mengetahui dunia dan tindakan para informan dan subjek penelitian kita dengan cara berjalan, bekerja, mendiskusikan hasil pengambilan gambar, makan, dan berbicara dengan informan. Hasil studi ini menunjukkan bahwa melalui penyelenggaraan Shalawatan, nabi Muhammad "dihadirkan dan dihidupkan" sesuai dengan interpretasi lokal majelis Syubbanul Muslimin. Acara "Shalawat Bersama" merupakan ritus agama dan/atau seni dalam Islam yang berbasiskan kesalehan sufistik: shalawat, doa (dzikir), dan barokah yang dikemas dari keinginan untuk mencintai menjadi semacam hasrat dalam moda kapitalisme lanjut.
\end{abstract}

Katakunci: Syubbanul Muslimin; kehadiran Nabi; hasrat; cinta 


\section{Pendahuluan}

Studi mengenai shalawat (devotional prayers) di Indonesia sudah banyak dilakukan dalam berbagai wilayah studi, cakupan analisis, dan sudut pandang. Penulis sempat kebingungan memahami studi-studi tersebut dikarenakan terdapat beragam konseptualisasi atau istilah yang dipakai: seni musik Islam, musik yang bernafaskan islam, musik rohani, musik bernuansa Islam, musik Islami (Rasmussen, 2010); seni berislam, ritual tradisi (Arafat, 2013); seni terbangun (Munawaroh, 2007); seni sholawatan, tradisi shalawatan (Susilantini, 2006); tradisi Islam (Abdullah, 1986; Abdullah dan Siddique, 1989); tradisi membaca sya'ir Islam (Kamaluddin, 2013); tradisi sastra profetik (Wargadinata, 2008); akulturasi Islam Jawa (Sumbulah, 2012; Ahyani, 2012); tradisi lisan/tradisi sastra pesantren (Muzakka, 2003); tradisi living hadits (Ilham, 2011); kesenian rakyat melalui rebana (Sinaga, 2001); popular music (Barendregt dan Zanten, 2002), popular culture (Fairuz, 2013), urban sufism (Howell, 2007; Woodward, dkk., 2012), prophetic cosmopolitanism (Hoesterey, 2012), new spiritual movement (Laksono, 1985), Islamic pop music/hybridization between pop culture and Islam (Nef-Saluz, 2007), Islamic sound (Foley, 2012), Arab spring (Foley, 2012; 2013), popular Islamic piety (Zamhari dan Howell, 2012); muslim music (Barendregt, 2006); mahabbah (Safi'i, 2013).

Komodifikasi shalawat berkaitan erat dengan bagaimana hubungan antara shalawat dan pasar dikonfigurasi. Komodifikasi shalawat merupakan konstruksi historis dan kultural yang kompleks, diproduksi dalam konteks kebudayaan tertentu, dan karenanya membutuhkan pemahaman terhadap kerangka kebudayaan untuk menyingkap signifikansi simbolik dan sosio-ekonomis dari majelis shalawat. Dalam konteks Syubbanul Muslimin, komodifikasinya tercermin dalam apa yang secara baik diistilahkan oleh Berger sebagai "kanopi sakral" (1969: 26). Dalam kanopi ini, para peserta Syubbanul Muslimin merasa berada dalam suatu kanopi, suatu kawasan imajiner yang di dalamnya mereka merasa terikat secara ukhrowi (cosmological) dan duniawi (mundane) dengan kekuatan shalawat.
Dalam majelis inilah, shalawat diperlakukan sebagai produk yang marketabel, dalam siklus moda transaksi dan reproduksi kapital, untuk memperlihatkan betapa fleksibel shalawat tersebut untuk memunculkan "kemungkinankemungkinan pesona religius" (Kitiarsa, 2008: 23).

Sosok Kiai Hafidzul Hakim Nur yang konon memiliki trah genealogis pada sayyid dan habaib dari Hadramaut memperlihatkan semacam citra hadrami diasporik dan barokah kenabian yang menubuh di dalamnya (embodied prophet blessing), memperkuat posisinya sebagai pimpinan majelis yang memiliki modal religius (religious capital) untuk melakukan gerakan religius melalui majelis Syubbanul Muslimin. Sayangnya, tidak semua peserta majelis memahami proses komodifikasi dalam majelis Syubbanul Muslimin tersebut, dan karena itulah mengapa studi ini penting untuk dilakukan.

\section{Metode}

Studi ini berusaha menempuh jalan memutar dengan pertama-tama menjustifikasi beberapa riset sebelumnya karena memosisikan kegiatan shalawat bersama sebagai arena reproduksi dan konsumsi modal religius melalui berbagai modal sosio-ekonomikultural, kemudian berusaha menggabungkan ketiganya dalam suatu studi yang mungkin masih bersifat hipotetis ini. Apa yang dilakukan oleh Woodward relevan dengan studi ini, tapi ia tidak secara spesifik memperlihatkan pola Hadhrami tersebut dalam konteks yang lebih spesifik. Begitu pula, khutbah Jum'at sebagai komoditas simbolik telah dengan baik disajikan dalam artikelnya Muzakki, namun secara empiris ia tidak menghubungkannya dengan reproduksi komoditas simbolik pada acara shalawat bersama.

Hal yang sama juga terjadi pada penelitian Barendregt dan Hirschkind yang secara spesifik hanya melibatkan media kaset sebagai sumber komodifikasi, sementara ada banyak sekali sarana produksi religius yang dimanfaatkan oleh majelis-majelis shalawat di Indonesia. Sementara itu, Fairuz dan Rosyid berfokus pada Ahbabul Mustofa di Solo dalam konteks kapitalisme lanjut, tetapi bagaimana ia 
berkaitan erat dengan komunitas Muslim diasporik di daerah pedesaan, seperti di Probolinggo, belum mendapat penekanan berarti. Dengan demikian, apa yang ditempuh oleh studi ini merupakan pengembangan dan pengayaan atas tiga studi di atas dan studistudi lain yang telah dan akan dijelaskan sepanjang riset ini.

Pendekatan yang digunakan, mengikuti pendapat Nur Rosyid (2015: 31), adalah antropologi inderawi. Pendekatan ini tidak hanya mengamati dan mengambil data, tetapi lebih dalam "menjadi" dan "terlibat" dalam cara-cara mengetahui dunia dan tindakan para informan dan subjek penelitian kita dengan cara berjalan, bekerja, mendiskusikan hasil pengambilan gambar, makan, dan berbicara dengan informan (Fauzanafi, 2013: 8). Pink (dalam Dicks, 2013: 8; bdk, Rosyid, 2015: 31) menegaskan etnografi inderawi merupakan proses berbagi pengalaman dan empati di mana pengalaman inderawi peneliti harus masuk ke dalam proses refleksi.

Salah satu konsekuensi menggunakan antropologi inderawi adalah penggunaan "partisipasi multi-inderawi" dan "wawancara multi-inderawi" (Rosyid, 2015: 32). Dalam partisipasi multi-inderawi, semua indera digunakan dan saling terkoneksi satu sama lain untuk mengumpulan data dari para partisipan. Sementara itu, wawancara multi-inderawi tidak semata-mata digunakan untuk mendapat pengetahuan, tetapi bagaimana pengetahuan itu tertancap ke dalam tubuh melalui penglihatan, cercapan, suara, bau, dan gerak tubuh itu sendiri (Fauzanafi, 2013: 13; bdk. Rosyid, 2015: 32).

\section{Diskusi dan Pembahasan}

\subsection{Safari Shalawat: "Hadir" dalam Gemuruh Kenabian \\ a. Safari 1: Gema Maulid di Wangkal Probolinggo}

Minggu, Malam Senin, 8 Januari 2017, penulis sempat menghadiri acara tabligh akbar bertajuk "Safari Maulid 40 Malam" yang menghadirkan muballigh Sayyidil Habib Abu Bakar Assegaf. Acara yang dihelat di Wangkal Gading Probolinggo ini diadakan oleh Majelis Syubbanul Muslimin dalam rangka memperingati Maulid Nabi Muhammad Saw. Lapangan Prasi Wangkal Gading Probolinggo yang menjadi tempat berlangsungnya acara tidak mampu menampung jumlah orang-orang yang hadir. Gang-gang dan jalan perkampungan sekitar harus ditutup untuk menampung peserta yang "membludak."

Melewati jalan masuk menuju Lapangan Prasi, para pedagang berjajar di kanan kiri jalan; menggelar lapak dengan sebuah meja; memajang poster-poster para habaib pun walisongo, berikut peci, buku-buku shalawat, kalender, tas, sarung, dan mukena. Beberapa lapak terdapat tumpukan kaset dengan DVD Player dan televisi kecil; memutar beberapa lagu shalawat bernuansa padang pasir; berbeda dengan suara shalawat yang dimainkan dari panggung-liriknya sebenarnya sama. Semerbak parfum Timur Tengah non-alkohol sesekali menusuk hidung, entah dari pengunjung yang berseliweran ata pedagang parfum itu sendiri; pun aroma jagung bakar dan tempura. Beberapa pedagang menjajakan plastik seukuran satu meter per segi sebagai alas duduk; menawarkannya kepada peserta yang tidak mendapatkan tempat yang disediakan. Penjual buku pun berkeliling di antara kerumunan; menawarkan kitab SimtudDuror, ad-Dibai, dan album-album shalawat Kiai Hafidzul Hakim Nur.

Lampu-lampu besar dipasang di setiap sudut mengikuti jalan dan tikar yang tergelar dari jalan masuk hingga panggung. Di sudutsudut jalan dan lapangan juga diletakkan speaker/sound system. Suara dari panggung dan obrolan jamaah yang datang, bercampur menciptakan situasi yang tampak 'berisik'. Beberapa proyektor terpasang yang pada saat bersamaan (live) menangkap situasi di panggung dan sekitarnya. Para penabuh, peserta yang bersorak-sorai, pejabat pemerintah, ulama-ulama, dan tokoh masyarakat sesekali tertampilkan dalam proyektor tersebut.

Peserta yang datang cukup beragam: muspika, muspida, dan tokoh masyarakat sudah berada di panggung; tiga puluhan lakilaki pengiring shalawat di panggung yang lebih rendah; anak-anak yang diajak orang tuanya; pemuda-pemudi dan santri datang rombongan; orang tua dengan pasangannya; ibu-ibu dengan anggota majelisnya; hingga mahasiswa dengan pacarnya atau temannya. Mereka berpakaian relatif sama: atasan putih, bawahan putih atau sarung hitam, peci atau kerudung putih, jaket berlogo Syubbanul Muslimin; atau cukup berbusana muslim. 
Peserta yang hadir tidak berdiri seperti konser musik pada umumnya. Masing-masing dari mereka duduk; lesehan. Diiringi musik rebana dari panggung kedua yang menghadap panggung utama, mereka bersama-sama membaca shalawat seusai ketua panitia selesai memberi sambutan. Sholawat pun dimulai; mahallul qiyam; dilanjutkan dengan bernyayi Allahumma salli wa sallim 'ala Muhammad. Akhirnya, acara ini diakhiri doa bagi yang berhajat; jamaah dilancarkan rejekinya; anakanak sekolah didoakan segera lulus dengan nilai yang baik; dan seterusnya.

Syubbanul Muslimin merupakan sebuah majelis shalawat yang berasal dari Kota Probolinggo, tepatnya di Desa Kotaanyar Sambirampak Lor, yang diasuh oleh Kiai Hafidzul Hakim Nur. Mengacu pada pandangan Zamhari dan Howell (2002: 50), apa yang disebut sebagai majelis sholawat dan majelis dzikir adalah sebuah komunitas dalam Islam yang selalu melakukan praktik resitasi (dzikir) dan pembacaan sholawat untuk mengingat kepada Tuhan dan mendoakan Nabi Muhammad.

Majelis shalawat dan pergelaran shalawat bersama yang diprakarsai oleh habaib (habibhabib) telah berkembang pesat di berbagai daerah di Indonesia. Tidak hanya majelis Ahbabul Musthofa yang diprakarsai oleh Habib Syech di Solo, di Jakarta ada Jama'ah Sholawat Majelis Rasulullah yang diprakarsai oleh (alm) Habib Munzir al-Musawa, di Boro juga berkembang Jamaah Shalawat Nurul Musthofa asuhan Habib Hasan bin Ja'Far Assegaf, di Pekalongan ada jamaah Kanzuj Shalawat yang diprakarsai oleh Habib Luthfi bin Ali.

Di Probolinggo sendiri, berbagai majelis shalawat juga bermunculan, mulai dari Majelis Ahbabul Musthofa asuhan Al-Habib Hasan AlMuhdlar di Kraksaan, Majelis Dlou'ul Mustofa asuhan KH Mas Imam di Kota Probolinggo, Majelis Al-Waly asuhan Lora Arifin di Kraksaan, Majelis Al-Barokah Wal-Kheir asuhan KH. Hasan Maulana di Genggong, termasuk juga Majelis Syubbanul Muslimin di Kotaanyar yang menjadi subjek penelitian ini karena di dalamnya penulis sering terlibat sebagai peserta majelis.

Banyak umat Muslim dari pedesaan mulai tertarik ikut bergabung dalam majelis maupun hadir dalam acara shalawat bersama itu. Ketertarikan jamaah tersebut jelas menunjukkan adanya suatu kecenderungan praktik dan cara menikmati sesuatu dalam
Islam. Sayangnya, selama ini kecenderungan studi mengenai shalawat telah mengkutub pada dua pandangan: aktivitas agama dengan aspek teologisnya dan aktivitas seni dengan isu-isu estetiknya. Belum ada studi yang secara spesifik menjelaskan kegiatan shalawat tersebut dalam konteks waralaba religius dan komunitas Muslim diasporik di Indonesia.

\section{b. Safari 2: Takbir Akbar Syubbanul Muslimin di Lapangan Paiton}

Sabtu malam, sontak gema takbir berkumandang di seluruh masjid dan mushalla setelah Menteri Agama Lukman Hakim Syarifuddin mengumumkan hari raya idul fitri jatuh pada minggu, 24 Juni 1917. Dalam kalender Hijriyah, karena pergeseran waktu dimulai maghrib, maka pada malam itu puasa ramadhan sudah berakhir dan memasuki hari raya Idul Fitri 1 Sawal 1438. Ada pemandangan yang berbeda malam Idul Fitri kali ini dengan tahun-tahun sebelumnya. Sepanjang Jalan Raya Panglima Sudirman yang menghubungkan kota Kraksaan dan Paiton yang biasanya macet dipadati ribuan manusia, kali ini nampak longggar sekalipun letusan kembang api tidak berkurang. Tempat-tempat yang biasanya menjadi konsentrasi pemudapun juga tidak seramai biasanya.

Penulis terus berjalan ke arah Timur menuju lapangan Paiton untuk menghadiri malam takbiran bersama Majelis Shalawat Syubbanul Muslimin. Setibanya di pertigaan paiton, barulah kepadatan lalu lintas mulai terasa. Terdapat puluhan mobil angkutan umum dan Pickup berjejer di pinggir jalan. Sementara beberapa petugas menggunakan rompi hijau mirip pakaian Polisi Satlantas tengah sibuk mengatur dan mempersilahkan ribuan orang memasuki lapangan.

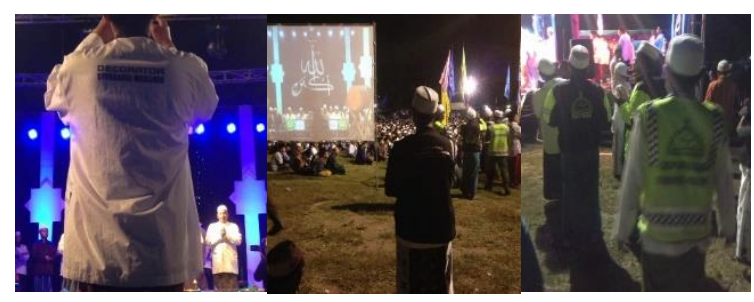

Gambar 4. Berbagai Kostum Pengurus Syubbanul Muslimin

(Sumber: Dok. Pribadi pada Malam Takbiran 24 Juni 2017)

Dari atribut yang mereka gunakan, tidak salah lagi, ada acara shalawatan majelis 
Syubbanul Muslimin. Para petugas yang mengatur lalu lintas tersebut sangat mudah dikenali. Rompi hijau dan jaket hitam yang mereka gunakan, terdapat logo besar Syubbanul Muslimin di punggungnya. Di bawah logo tersebut tertulis bidang pekerjaan mereka seperti "keamanan" atau bidang lainnya. Kemudian ada juga yang menggunakan baju koko warna putih dan jaket hitam tanpa kombinasi yang juga dilengkapi tugas pokok masing-masing.

Memasuki lapangan, di pinggir pintu masuk, berbagai atribut subbanul muslimin dipajang di lapak kecil, sekurang-kurangnya berukuran 4X4. Lapak itu dijaga oleh petugas yang juga memakai seragam khusus dengan tulisan 'koperasi' lengkap dengan nama petugasnya. Dengan luas lapak seperti itu, mereka terlihat kewalahan melayani banyaknya jamaah yang hendak membeli bermacammacam barang dagangannya. Jenis barang yang dijual sebenarnya tidak begitu bervariasi, hanya minyak wangi, stiker, baju koko, peci, payung, shal/surban, yang semuanya dilengkapi dengan logo atau tulisan subbanul muslimin.

Sedangkan yang paling diburu jamaah adalah puluhan album lagu-lagu Syubbanul Muslimin dalam bentuk VCD lengkap dengan tema album dan tempat kegiatan dilangsungkan, dijual dengan harga 10 ribu perkeping. Yang tidak kalah laris adalah air mineral dengan tulisan SubbanQ, dijual 5 ribu perdua botol. Di lapangan Paiton tersebut, hanya ada satu lapak, yakni lapak koperasi Syubbanul Muslimin. Barang daganganpun juga hanya terdiri dari satu brand, yakni brand Syubbanul Muslimin dalam berbagai produk.

Melihat ke arah panggung, lapangan seluas ukuran lapangan sepakbola tersebut sudah dipadati ribuan manusia. Sejauh mata memandang, yang terlihat hanya kerumunan manusia yang diantaranya menggunakan peci dan bendera dengan logo dan tulisan besar sebagaimana yang terdapat dalam atributatribut lainnya. Kibaran bendera dalam berbagai warna tersebut mirip konser-konser musik grup band ternama atau kampanye partai politik. Dalam kerumunan itu, banyak dari kalangan ibu-ibu dengan usia yang cukup beragam dan berbagai latar belakang pemuda yang mendominasi jamaah baik dari kalangan santri maupun abangan bersatu memanjatkan takbir dan shalawat.
Identifikasi sederhana terhadap jemaah apakah mereka dari kalangan santri atau abangan cukup dilihat dari penampilannya. Meski rata-rata menggunakan peci, tetapi ada beberapa jamaah yang rambutnya diwarnai dan telinga yang ditindih dan dipasangi anting. Penampilan seperti ini jelas tidak lumrah di kalangan santri. Tetapi menariknya, Mereka dapat bersatu dan melupakan sekat-sekat perbedaan di antara mereka. Melalui kegiatan shalawatan tersebut seakan para jamaah sejenak berada komunitas yang sama tanpa diferensiasi dan stritafikasi.

Meski terdapat ribuan jamaah yang memadati lapangan, seluruh lantunan shalawat dan lagu-lagu islami, nasihat baik (mauidzah hasanah), dan do'a-do'a yang dipanjatkan sangat jelas terdengar. Terdapat sound sistem yang di pasang di kanan dan kiri pentas dan di sela-sela tempat duduk sebelah kanan dan kiri lapangan. Orang-orang yang ada di pentas juga dapat dilihat dengan jelas karena dibantu oleh 4 layar proyektor yang dipasang di tempattempat yang agak jauh dari panggung. Begitu pula dengan ribuan jamaah yang dengan sabar duduk bersama juga mendapatkan sinar yang cukup dari deretan lampu neon yang sudah di pasang di berbagai posisi dan sesekali mereka mendapatkan sinar warna warni dari lampu sorot yang terus bergerak secara teratur.

Sementara panggung dengan ukuran $12 \times 8 \mathrm{~m}$, begitu tertata dengan baik. Tidak ada kesan sama sekali yang menunjukkan panggung terlalu luas. Warna background, dekorasi, tangga penyangga yang didesain mirip tangga masjid, penempatan lampu, semuanya nampak serasi bersama pancaran lampu warna warni yang cukup memberikan sinar terang bagi luasnya panggung. Begitu juga dengan logo dan tulisan Syubbanul Muslimin nampak jelas dipasang pada beberapa meja kecil yang memanjang persis berada di bagian depan tempat duduk orang-orang khusus yang dianggap pantas berada di atas pentas. Pada malam itu diisi para habaib, para gus-gus (putra-putra kiai yang masih muda), termasuk pimpinan Syubbanul Muslimin Gus Hafidz (sebutan akrab KH. Hafidzul Hakim Nur), para vokalis dan panabuh musik hadrah.

Kesan malam takbiran pun sangat terasa dengan adanya sepasang bedug yang diletakkan di bagian depan pentas yang menjulang ke penonton. Dekorasinyapun disesuaikan dengan momentum malam hari 
raya. Terdapat lafadz Allahu Akbar dalam kaligrafi bahasa Arab yang ditulis cukup besar, tapi tetap simetris. Tidak lupa di bagian atas pentas terdapat tulisan, "Keluarga Besar Majelis Ta'lim dan Shalawat Syubbanul Muslimin Mengucapkan Selamat Hari Raya Idul Fitri.

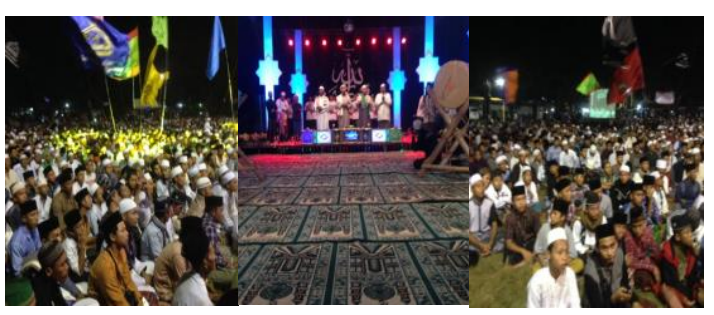

Gambar 5. Kondisi Jamaah dan Panggung Shalawatan

(Sumber: Dok. Pribadi pada Malam Takbiran 24 Juni 2017)

Pembacaan takbir yang diiringi musik dan dalam momen-momen tertentu kembang api secara beruntun ditembakkan ke atas, menambah suasana kian menghibur. Pembacaan shalawat simtuddurar dan beberapa lagu baru ciptaan Syubbanul Muslimin sendiri baik dalam lirik Arab maupun bahasa Indonesia dilantunkan dengan ritmis bersama iringan musik rabbana. Dalam beberapa saat jamaah ikut melantunkan bacaaan pada shalawat-shalawat yang sudah dihafal liriknya. Yang paling ramai, ketika lagu-lagu ciptaan Syubbanul Muslimin sendiri dilantunkan dengan aransemen yang sangat berbeda dengan irama rabbana al-banjari, nyaris membuat jamaah yang muda-muda berjoget. Beruntung ada petugas yang selalu siap mengarahkan senter pada siapapun yang berdiri dan berjoget, sehingga jamaah hanya mencukupkan diri dengan mengangkat/menggoyangkan tangannya.

Kendati demikian, rangkain acara tidak hanya menunjukkan kemasan meriah melalui senandung shalawat dan lagu-lagu dengan irama riang gembira. Lebih dari itu, juga terdapat beberapa bagian acara yang menunjukkan kesan penuh khidmat dan khusu'. Di tengah-tengah acara, terdapat munajat bersama, dimana tidak ada seorangpun yang berbicara, hingga yang nampak adalah keheningan. Bagitu juga dengan lagu-lagu yang dibawakan, sebagian lagu ada yang bergenre slow islami yang berisi pesan-pesan moral yang sangat kuat. Seperti ketika lagu Rindu Ayah dinyanyikan, tidak hanya para vokalis tetapi sebagian jama'ahpun sampai meneteskan air mata.

Belakangan ini, penyelenggaraan acara shalawatan dalam ruang publik seperti di atas, semakin sering dan terlihat mulai menggeser konser-konser musik seperti dangdutan dan band-band ternama ibu kota. Setiap acara sepertinya tidak pernah sepi pengunjung (jamaah). Kondisi ini juga diikuti oleh berdirinya majelis-majelis shalawat yang hari ini tidak terhitung jumlahnya di Kabupaten Probolinggo.

Eksistensi majelis shalawat tersebut terus berkembang dengan jumlah jamaah yang terus bertambah. Di Kabupaten Probolinggo, terdapat banyak sekali majelis sholawat seperti Syubbanul Muslimin, Alwaly, Nurul Mukhtar, Hubbun nabi, Lahar Mania, Arrasul, Annur, dan lain sebaginya. Dua nama paling awal merupakan yang terlama dan terbesar. Keduanya juga memiliki kegiatan rutin paling sering dilaksanakan yaitu minimal 2 kali dalam seminggu dan normalnya 1 kali dalam seminggu. Sementara yang lain cenderung kondisional tergantung undangan.

Secara umum sasaran jamaah majelis shalawat adalah pemuda dengan latar belakang yang berbeda-beda. Sudah menjadi pemandangan umum, setiap ada shalawatan yang digelar oleh majelis shalawat tertentu, terdapat sejumlah pemuda naik motor bersama dengan memakai baju, peci, dan bendera yang bertuliskan atau bergambar lambang majelis sholawat tersebut. Penggunaan, popularisasi, dan penyebaran shalawat melalui berbagai majelis shalawat sepertinya telah menjadi trend baru bersama meningkatnya budaya pop dalam agama. Fenomena ini melengkapi trend kebangkitan keagamaan yang belakangan ini semakin banyak menjadi sorotan dunia.

\section{2. "Kehadiran" Nabi dalam Syubbanul Muslimin}

Di tangan majelis shalawat seperti Syubbanul Muslimin, shalawat dihadirkan dalam bentuk yang mengibur dan menyenangkan. Shalawat tidak lagi dibaca hanya untuk konsumsi spiritual sebagaimana nilai-nilai tradisionalnya, melainkan dipentaskan dalam panggung-panggung yang besar dan megah yang tentu membutuhkan biaya yang cukup besar. Ungkapan kecintaan yang mengintegrasikan nilai-nilai hiburan dan komersialisme yang cenderung dianggap bertentangan dengan nilai-nilai agama dengan 
spiritualitas yang cenderung dianggap suci, justru menjadi potret religiusitas jamaah majelis shalawat hari ini. Lebih luas percampuran paradoks berbagai nilai tersebut merupakan fenomena yang umum yang terjadi dalam praktek-praktek religiusitas lainnya atau bahkan terjadi di semua agama. Dalam agama Kristen, fenomena hibridasi ini dieksplorasi oleh David Lyon dalam bukunya Jesus in Dineyland, Relegion in Postmodern Times.

Dalam arti yang sebenarnya, Jesus in Dineyland merupakan istilah yang bermula dari Perayaan Harvest Day Crusade di Disneyland, Anaheim, California yang mampu menarik 10.000 pengunjung (Lyon, 2000). Perayaan regular tersebut menjadi tempat atraksi para seniman Kristen dan para pengjil, serta Yesus yang dihadirkan dalam gambar-gambar berbeda dengan kebanyakan seperti Yesus bersama kartun-kartun dan berdampingan dangan rahib dan dewa Hindu. Gambar-gambar ini tentu sangat mencolok dan berbeda dengan citra Yesus pada umumnya yang nampak suci.

Dalam arti lain Jesus in Disneyland dikiaskan sebagai tempat pertemuan nilai-nilai yang secara teleskopis berbeda baik historis maupun kultural. Pertemuan nilai spiritualitas yang suci, mesterius, dan private diungkapkan dengan aktivitas menghibur dan menyenangkan yang oleh sebagain orang Kristen dianggap bertentangan dengan kekristenan itu sendiri. Disneyisasi bagi Lyon bersifat universal dan menjadi potret keagamaan zaman postmodern, sehingga shalawatan yang dipublikasi dan dipertontonkan dengan suasana menghibur juga menunjukkan bagian dari disneyisasi. Demikian juga Perayaan Harvest Day Crusade di Disneyland yang menunjukkan fenomena sengkarut nilai, dimana sosok Yesus dengan bebas dilukis berdasarkan interpretasi lokalitas Disney, juga bisa menjadi contoh pegelaran even-even shalawat.

Dalam penyelenggaraan Shalawatan, nabi Muhammad juga "dihadirkan dan dihidupkan" sesuai dengan interpretasi lokal majelis Syubbanul Muslimin. Nilai-nilai kemuhammadan seperti kisah, tauladan, dan segala ajaran, dan mu'jizatnya dipahami dan diproduksi dalam teks-teks shalawat dan lagulagu islami yang dilantunkan dalam irama dan iringan musik tertentu. Pegelaran ini akhirnya menjadi even menyambut "kehadiran" nabi
Muhammad saw dalam kultur religiusitas yang diproduksi Syubbanul Muslimin.

\subsection{Syubbanul Muslimin: Otentisitas Kehadiran "Nabi"?}

Shalawat (durûd) sebagai ungkapan do'a atau pujian terhadap nabi Muhammad pada dasarnya berakar langsung pada al-Qur'an surat al-Ahzab (33):56. Dalam ayat tersebut, Allah dan para malaikat bershalawat untuk nabi dan setiap orang yang beriman dianjurkan bershalawat terhadapnya. Sedangkan bentuk ungkapan sederhana shalawat kepada nabi bagi orang yang beriman adalah dengan mengucapkan shallâ al-Allâh alaih wa sallam (semoga Allah memberikan shalawat dan salam kepadanya [nabi]). Ungkapan sederhana ini biasanya diucapkan setiap mendengar atau mengucapkan nama nabi disebut.

Dalam perjalanannya, cara dan kalimat yang baik dan indah untuk memuji nabi terus berkembang. Jenis-jenis shalawat terus dihasilkan hingga terdapat puluhan jenis shalawat, seperti shalawat ma'tsûrah, ibrâhîmiyyah, fâtih, qathb al aqthâb, ummî, nariyah, dan lain-lain. Bahkan ada yang telah dibukukan seperti, shalawat dalâ'il, bakriyah, al-dibâ'i, dan simthu al-durâr. Dua kitab shawalat terakhir biasaya dibaca pada acara mauludan (ulang tahun nabi) dengan iramairama tertentu dan tidak jarang diiringi musik rabbana (hadrah).

Dalam khazanah keilmuan Islam, terdapat perbedaan pandangan mengenai hukum dan tata cara mengucapkan shalawat. Sebagian ulama' ada yang mengatakan wajib mengucapkan shalawat sekali sepanjang hidup dan sebagiannya lagi mengatakan kata amr dalam surat Al-Ahzâb tersebut bermakna anjuran kecuali yang telah disyari'atkan sebagaimana shalawat dalam shalat. Dalam konteks ini, perbedaan hukum membaca shalawat tidak begitu mengalami pertentangan, karena hanya berbeda pada tingkat keharusan membaca shalawat.

Kontroversi shalawat dalam Islam lebih khusus terletak pada tata cara pembacaan shalawat yang hari ini dilakukan dengan mengkolaborasikan dan mengintegrasikan unsur-unsur kebudayaan tertentu, seperti kesenian, sistem kepercayaan, sistem pemikiran dan lain sebagainya. Penerimaan terhadap unsur-unsur kebudayaan (sinkretisitas) dalam pembacaan shalawat 
dapat dibuktikan dalam ritual perayaan maulid nabi dan acara-acara selamatan. Ritual-ritual ini tidak sekedar untuk membaca shalawat setiap nama nabi disebut atau didengar, melainkan juga dilakukan untuk memperingati kelahiran anak dan selamatan lainnya.

Penolakan yang paling keras datang dari kelompok-kelompok puritan (seperti wahabi dan Muhammadiyah) yang umumnya tidak menghendaki adanya inovasi (budaya) dalam ibadah. Praktek-praktek pembacaan shalawat dalam berbagai kegiatan kebudayaan dianggap sebagai bid'ah yang sangat dilarang dalam Islam. Sikap ini dapat ditemui dari beberapa tulisan tokoh-tokoh wahabi yang dipublikasikan dalam situs resmi wahabi http.//asysyariah.com atau dalam jurnal Asy Syariah.

Salah satu tokoh Wahabi Saifuddin Zuhri Purwokerto dalam khutbahnya mengatakan:

"Cinta seseorang kepada Rasulullah pun tidak diwujudkan dengan merayakan hari kelahiran beliau. Karena perayaan tersebut adalah amalan ibadah yang diada-adakan dalam agama Islam... Oleh karena itu, merayakan hari kelahirannya adalah perbuatan bid'ah karena hal itu adalah perkara baru yang diada-adakan dalam agama, tidak pernah dilakukan oleh Rasulullah dan para sahabatnya yang mulia, seperti Abu Bakr, 'Umar, 'Utsman, 'Ali, dan yang lainnya. Begitu pula, tidak pernah dirayakan oleh generasi terbaik berikutnya dari kalangan tabi'in serta imam yang empat: Abu Hanifah, Malik, asy-Syafi'i, Ahmad, dan para imam Ahlus Sunnah berikutnya rahimahumullah." (Syaifuddin Zuhri, "Maulid Nabi, Bukti Cinta Rasul?", 2012)

Begitu juga dalam tulisan Abu Karimah Askari Makassar menganggap perayaan maulid nabi, beberapa jenis shawalat, dan segala jenis wiridan hasil karya para sufi merupakan bentuk bid'ah. Bahkan praktek-praktek tersebut dianggap justru menghalangi orang muslim untuk mendekatkan diri kepada Allah (Askari, 2011).

Namun bagi kalangan Islam tradisonal (kelompok Islam yang dalam kondisi-kondisi tertentu cenderung menerima percampuran agama dan budaya), bid'ah (inovasi) diterima sejauh tidak menyangkut ibadah-ibadah mahdhah yang tata cara dan waktunya telah ditetapkan. Artinya di luar shalat, puasa, haji dan ibadah mahdhah lainnya, boleh melakukan inovasi selama perbuatan-perbuatan tersebut tidak pernah dilarang meskipun tidak pernah diperintah atau dilakukan oleh nabi. Bagi Islam tradisional pembacaan shalawat dalam berbagai acara selamatan adat dianggap tidak mengurangi kesunnahan membaca shalawat, sekalipun dibaca dengan nada atau iramairama dan diiringi musik-musik tertentu yang tidak dilarang dalam Islam. Sehingga, pembacaan shalawat seperti al-dibâ'i dan simthu al-durâr dalam berbagai acara ritual adat menjadi salah satu bagian dari religiusitas Islam tradisional.

Sekalipun demikian, percampuran budaya dalam membaca shalawat tidak serta merta hanya sebagai produk kebudayaan baru yang tidak memiliki pijakan historis pada zaman nabi. Jika ditelusuri, tata cara dan penggunaan musik bagi Islam tradisional didasarkan pada prilaku dan tradisi yang sudah berkembang sejak zaman nabi. Seperti musik rabbana, sudah berkembang sejak zaman nabi dan tidak pernah ia melarangnya. Contoh yang paling jelas dalam sejarah adalah ketika nabi tiba di madinah, ia disambut dengan tabuhan rabbana. Bagitu juga tata cara pembacaan shalawat yang dilakuan dalam keadaan berdiri juga didasarkan pada prilaku para sahabat termasuk Fatimah ketika menyambut nabi yang dikabarkan dalam keadaan berdiri. Perilaku ini dimaknai sebagai penghormatan kepada nabi.

Bagi kalangan islam tradisional, membaca sholawat dalam keadaan apapun tetap mendapatkan manfaat yang tidak terhinggga. Ibnu Qayim al-Jauziyah yang banyak dijadikan rujukan bagi yang meyakini manfaat membaca shalawat, memuat banyak sekali manfaat membaca shalawat, diantaranya; membaca shalawat dapat memperbaiki ingatan, memberantas kemiskinan dan kelaparan, mengurangi semua kesulitan hidup, menyelesaikan semua masalah, memberikan keamanan di dunia dan di akhirat, mengkompensasi 10 dosa, mengkompensasi semua dosa, membatalkan perbuatan buruk 200 tahun, memberi hadiah yang setara dengan sebuah amal, memberikan penghargaan yang setara dengan gunung Uhud, dan lain sebagainya (Al-Jauziyah, 1987).

Keyakinan akan manfaat membaca shalawat, membuat shalawat terus eksis dan 
berkembang dalam setiap peradaban Islam. Peringatan maulid nabi yang mulanya dilakukan oleh Shalahuddin al-Ayyubi dengan sekedar menceritakan ketauladanan nabi untuk membangkitkan semangat tempur umat islam dalam perang salib, terus berkembang menjadi kegiatan rutin dalam setiap kelahiran nabi. Kemudian sejak abad ke-13 M sampai sekarang, khususnya setelah Imam al-Diba'i dan Habib Ali berhasil menyusun kitab al-dibâ'i atau simthu al-durâr yang memuat kumpulan shalawat dan kisah-kisah nabi, peringatan maulid nabi dilakukan dengan membaca dua kitab karya dua ulama' besar tersebut.

Pembacaan kitab-kitab tersebut terus berkembang dan berintegrasi dengan berbagai perkembangan zaman. Semula shalawatan hanyalah bagian dari kegiatan rutinan 1 atau 2 kali dalam seminggu sebagaimana tahlilan, yasinan, sarwaan, pengajian rutin malam seninan, selasaan, dan lain-lain, istighâsah, manaqiban dan tradisi keagamaan lainnya, tetapi akhir-akhir ini berkembang menjadi kegiatan besar "Shalawat Bersama" yang menghibur sebagaimana yang diselenggarakan oleh majelis-majelis shalawat, seperti Syubbanul Muslimin.

\subsection{Dari Cinta hingga Hasrat terhadap Kehadiran Nabi}

Acara "Shalawat Bersama" merupakan ritus agama dan/atau seni dalam Islam yang berbasiskan kesalehan sufistik: shalawat, doa (dzikir), dan barokah. Berkembangnya acara tersebut terjadi berbarengan dengan pembentukan majelis shalawat yang diprakarsai oleh habaib di Indonesia. Keberadaan habaib memainkan peran penting dalam pembentukan etos religiusitas-estetis Islam kontemporer melalui acara shalawat bersama sebagai upaya membawa "kedamaian". Gagasan kedamaian sebagai ide islamisasi nusantara dihadirkan kembali dalam acara shalawat bersama.

Ide mengenai "kedamaian" menjadi "nilai" yang dilekatkan, atau sesuatu yang terkomodifikasi ini dilangsungkan atau ditegaskan melalui pergelaran, yang secara simultan membentuk strandarisasi orang (audiens) dalam "mengalami" shalawat tersebut. Kedamaian yang dibentuk dan dikelola melalui bershalawat bersama tersebut, dialami secara ketubuhan dan kerja penginderaan mereka, yang secara simultan mendorong orang memproduksi hasrat kepuasannya sendiri. Hal tersebut tercermin di dalam bagaimana masing-masing audiens memahami partisipasi mereka, entah yang hanya diam, bergoyang-goyang, melihat fans, atau mengibarkan bendera. Kedamaian dapat kita pahami suatu kategori kondisi yang dibentuk melalui kecenderungan tubuh yang tidak secara langsung diungkapkan dengan konsep "damai" itu seperti apa, tetapi dipahami dalam pemenuhan hasrat mereka melalui pengalaman ketubuhan dan penginderaan yang kompleks dan bersinestesis, seperti perasaan luwih seneng, mantep, luwih mlebu, ben iso cetho, hawane sembribit, ben ora garing, dan lain sebagainya.

Orang-orang Muslim, utamanya Nahdlatul Ulama, dimobilisasi untuk hadir ke acara Shalawat Bersama melalui pembentukan hasrat dengan beragam cara agar turut berpartisipasi dalam acara tersebut. Bentuk-bentuk pengkondisian ini terjadi pada acara yang dilaksanakan di tanah lapang dengan didudukkan dan ditata sedemikian rupa dengan menghadirkan atribut-atribut material, panggung "megah", paket pesanan sound system dan proyektor dan pembuat film. Keberadaan OHP, misalnya, menjadi salah satu faktor penting dalam upaya 'mendekatkan' audiens dengan performer melalui kecenderungan visualitas. Demikian juga dengan keberadaan material-material lain yang mempunyai kapasitas sensorialnya agar turut memberi pengaruh yang signifikan dalam membangun partisipasi audiens.

Keberadaan acara "Shalawat Bersama" yang dirutinkan oleh Majelis Syubbanul Muslimin telah mentransformasi hasrat orang Muslim belakangan ini. Dalam konteks kapitalisme lanjut, pembentukan hasrat bershalawat dibentuk dari standarisasi penginderaan yang dikondisikan dan disituasikan secara hiperestesis: dibombardirkannya sensasi terus menerus. Mereka tidak lagi menjadi muslim taat dengan "menjadi pendengar" atau istilah dalam Islam "Sami'na wa Atho'na" (kami mendengarkan dan mentaati). Pembentukan hasrat ini dimungkinkan adanya pengelolaan majelis secara waralaba, dimana pusat memainkan peranannya dalam menopang model penyelenggaraan acara. Subyek-subyek ini secara langsung terdorong me(re)produksi ingatan-ingatan yang berharga dari kehadiran 
mereka selama acara Shalawat Bersama. Ingatan dan sensasi tersebut direproduksi ke dalam kehidupan sehari-hari, entah dalam rutinan diba'an di pondok, memasang foto di rumah, mendengarkan shalawat, menyimpan foto dan mengunggahnya di facebook, dan sebagainya.

Terbentuknya hasrat kecenderungan beribadah dan/atau seni tersebut terus menerus di(re)produksi karena dimungkinkan, dikondisikan, dan disituasikan oleh sejarah panjang perjalanan habaib berindigenisasi dan berdiaspora di Indonesia. Berkembangnya majelis shalawat sebagai gerakan sosial dalam kontestasinya di ruang publik tidak hanya terjadi melalui upaya mereka mengatasi perdebatanperdebatan dan penolakan mengenai ritus shalawat secara diskursif. Upaya Hadrami mengisi (occupy) ruang publik di Indonesia dilakukan melalui ritus pelembagaan acara Maulid (Shalawat Bersama) yang dikenalkan mulai tahun 1970an oleh Habib Al-Habsyi merupakan arena bagi pelembagaan keberadaan Hadrami itu sendiri. Acara ini tidak hanya diselenggarakan sebagai salah satu ibadah dan apresiasi kecintaan kepada nabi, tetapi juga arena pelegitimasian genealogi sayyid dan eksklusivitasnya yang secara historis dibentuk oleh situasi politik negara semenjak kepemimpinan Presiden Soeharto.

Eksklusivitas genealogi sayyid terbentuk melalui sikap Negara, terutama semasa Presiden Soekarno. Negara melakukan "pembatasan" hubungan antara orang pribumi dengan orang Hadrami dengan memunculkan sentimen yang dikenal dengan antiHadramautisme. Pembatasan ini sebenarnya Negara "membiarkan" mereka sebagai implikasi sikap negara untuk mengutamakan pribumi. Pada kondisi ini Hadrami terbatas untuk melakukan hubungan amalgamasi dengan pribumi agar hubungan mereka lebih dekat.

Sentimen Hadramautism inilah yang justru memungkinkan pendakwah Hadrami bisa mengeksplorasi modal genealogi sayyid dalam indigenisasi atau berdiaspora dengan Muslim pribumi. Model pernikahan endogami tersebut, membuat Hadrami, terutama yang bergelar "habib" yang disebut-sebut sebagai keturunan nabi, seolah-olah dapat mempertahankan "darah" kenabian.

Akhir situasi orde baru, mereka mulai mengadakan acara Maulid yang diprakarsai oleh pengarang kitab simtudduror, Habib Al Habsyi. Penyelenggaraan acara ini mendapat pertentangan dari kelompok Islam lain, selain $\mathrm{NU}$, mengenai boleh atau tidaknya bershalawat. Karena berbagi praktik recitasi yang sama inilah, Hadrami mulai berindegenisasi di Indonesia. Perkembangan Hadrami diaspora ini menunjukkan adanya dua persinggungan penting, yaitu komitmen bersama untuk dakwah secara damai, yang dikenal dengan amar ma'ruf (mengajak kepada kebaikan) dan penghormatan bersama untuk orang-orang (di)suci(kan). Al-Habsyi mengupayakan penggabungan "tradisi" dengan gagasan genealogi sayyid sebagai perwujudan esensi kenabian dan barokah yang dihasilkan melalui pergelaran maulid (Shalawat Bersama).

Proses indigenisasi Hadrami terus berlanjut melalui pelembagaan secara organisasional di daerah-daerah dengan melibatkan kooperasi antara Hadrami dengan ulama lokal maupun jajaran pemerintah di dalam acara Shalawat Bersama. Di samping itu, mereka juga mengembangkan tiga kitab recitasinya dengan lagu-lagu yang dikarang oleh ulama Indonesia. Pada titik inilah acara Shalawat Bersama dapat dikatakan sebagai sebentuk ritus penginstitusian (rites of institutions). Pelembagaan batas-batas arbiter dibentuk melalui pengelolaan modal-modal religius dan sosial Hadrami, bahwa tidak ada batas tegasnya dengan NU. Namun, peleburan batas Hadrami dan NU ini justru mempertegas batasnya dengan "kelompok Islam lain" sebagaimana pengalaman Umar. Di samping itu, dapat kita pahami, pergelaran Maulid dan acara Shalawat Bersama membaca Simtudduror tidak hanya dilangsungkan sebagai bentuk perayaan kelahiran Nabi Muhammad, tetapi juga-secara politisperayaan merupakan pelembagaan untuk meneguhkan genealogi sayyid. Pelembagaan ini berkaitan penting dengan perkembangan majelis AM di berbagai daerah dan pelaksanaan acara Shalawat Bersama.

Acara Shalawat bersama sebagai arena pelegitimasian genealogi sayyid dan aspek teologis Islam terus berkembang mengikuti logika pemasaran modern. Mereka tidak hanya menggunakan produk industri kebudayaan populer, seperti: internet dan industri perekaman. Logika pemasaran yang saya temukan di sini ialah-sengaja atau tidakmengikuti logika pemasaran waralaba 
(franchise) sebagai model manajemennya. Majelis Shalawat Syubbanul Muslimin yang dibentuk oleh Gus Hafidz mulai didirikan cabang-cabang (Syubban Lovers Nusantara) di berbagai daerah yang berafiliasi dengan Syubbanul Muslimin Pusat melalui proses "peresmian" oleh Gus Hafidz sendiri dibantu oleh habaib lain. Manajemen tersebut memungkinkan adanya pengelolaan grup-grup rebana di berbagai daerah menjadi persis dengan grup rebana di Pusat (Kalikajar Probolinggo). Di samping itu, pengelolaan yang diserahkan di tingkat lokal, memungkinkan Gus Hafidz dapat terus hadir di masyarakat secara rutin dan berpindah-pindah. Hal ini didukung oleh bentuk penguasaan lagu sesuai dengan ketentuan pusat, sebagai modal utama keberlanjutan grup-grup rebana.

\section{Penutup}

Sebagaimana diklaim banyak akademisi, agama telah terkomodifikasi dan menjadi sesuatu yang bisa "dikonsumsi". Hal ini bukan berarti "buruk" atau agama telah kehilangan "ruh" karena terjual. Dalam konteks pendirian majelis shalawat di Indonesia, logika pemasaran waralaba sebagai logika pengembangan ekonomi (akumulasi modal, sirkulasi modal) menandakan telah masuk ke dalam aktivitas religius. Perlu ditekankan lagi, di sini penulis tidak membahas sejauhmana akumulasi dan sirkulasi modal terjadi dalam tumbuhnya majelis shalawat di Indonesia.

Akan tetapi, penulis memfokuskan pada proses pembentukan etos konsumsi yang pada dasarnya sama dengan pembentukan hasrat dalam bershalawat. Pembentukan etos konsumsi melalui pengelolaan hasrat dalam aktivitas shalawat bersama ternyata tidak jauh berbeda dengan bagaimana kapitalisme lanjut (late capitalism) bekerja membentuk konsumerisme belakangan ini. Hasrat subyeksubyek ini tidak hanya dikonstruksi melalui berkembangnya waralaba religius dan acara Shalawat Bersama. Di lain kesempatan, subyek-=subyek mereproduksinya dalam bentuk yang beragam sesuai dengan hasrat tertentu yang ingin diraihnya sesuai persepsi pengalaman penginderaan dan ketubuhan dalam relasi sosial dan lingkungan tertentu.

\section{Daftar Pustaka}

Abdullah, I. (1986). Arti Simbolis Gunung Kakung pada Upacara Gerebeg: Suatu Kajian tentang Pandangan Hidup Jawa. Yogyakata: Fakultas Sastra UGM Yogyakarta.

Abdullah, T. (1989). "Islam dan Pembentukan Tradisi di Asia Tenggara", dalam Taufik Abdullah dan Sharon Siddique. Tradisi dan Kebangkitan Islam di Asia Tenggara. Jakarta: LP3S.

Ahyani, S. (2012). "Islam Jawa: Varian Keagamaan Masyarakat Muslim dalam Tinjauan Antropologi." Jurnal Salam, (15)1, Juni, 28-39.

Al-Jauziyah, I. Q. (1987). Jalâ'ul Afhâm Fî Fadl al Shâlat Wa al-Salâm Alâ Khair alAnâm. Kwait: Dâr al-'Urûbat Li alNasyr wa al-Tauzî'.

Arafat, Y. M. (2013). "Tarekat Tilawatiyah: Melantunkan Al-Quran'an, Memakrifati Diri, Melankonkan Islam." Tesis. Yogyakarta: Fakultas IImu Budaya UGM Yogyakarta.

Askari, A. K. (2011). "Shalawat-shalawat Bid'ah" http.//asysyariah.com, 14 November.

Barendregt, B. (2006). "The Changing of Art of Seduction: Ritual Courtship, Performing Prostitutes, Erotic Entertainment." IIAS (International Institute for Asian Studies) Newsletter 40, 1-5.

Barendregt, B., \& Zanten, W. V. (2002). "Popular Music in Indonesia since 1998, in Particular Fusion, Indie, and Islamic Music on VideoCompact Discs and the Internet." Yearbook for Traditional Music, 34, 67-113.

Berger, P. L. (1967). The Sacred Canopy: Elements of a Sociology of Religion. New York: Doubleday. 
Berger. (1999). "The Desecularization of the World: A Global Interview," dalam P. L. Berger (ed.), The Desecularization of the World: Resurgent Religion and World Politics. Washington, DC: The Ethics and Public Policy Center, 1-18.

Dicks, B. 2003. "Action, Experience, Communication: Three Methodological Paradigms for Researching Multimodal and Multisensory Settings." Qualitative Research Online. Diakses dari http://qrj.sagepub.com/content/early L2013/09/10/1468794113501687, 10 Februari 2017.

Fairuz, R. (2013). "Maulid and Shalawat in Popular Culture Perspective: Study of Jamaah Ahbabul Musthofa Yogyakarta." Research Paper. Yogyakarta: Fakultas Adab dan Humaniora, UIN Sunan Kalijaga Yogyakarta.

Fauzanafi, M. Z. (2005). Reog Ponorogo: Menari di antara Dominasi dan Keragaman. Yogyakarta: Kepel Press.

Foley, S. (2012). "The Latent Desire: The Arab Spring and the Rise of the New Order in the Middle East and the Modern World." Paper sponsored by the IIUM Academic Staff Association and the Department of Political Science, Kulliyah of Islamic Revealed Knowledge and Human Sciences. Malaysia: International Islamic University Malaysia.

Foley, S. (2013). "The Gulf and the Arab Spring: An American's Perspective," Paper presented to the Saudi Arabian Ministry of Foreign Affairs Institute of Diplomatic Studies. Riyadh, Arab Saudi.

Hoesterey, J.B. (2012). "Prophetic Cosmopolitanism: Islam, Pop Psychology, and Civic Virtue in Indonesia". City and Society, 24(1), 38-61. DOI : 10.1111/j.1548744X.2012.01067.x
Hoesterey, J.B. (2016). Rebranding Islam: Piety, Prosperity, and A Self-Help Guru. California: Stanford University Press. DOI : $10.1355 / \mathrm{sj} 32-2 \mathrm{~m}$

Hoesterey, James B. (2008) "Prophetic Cosmopolitanism: Islam, Pop Psychology, and Civic Virtue in Indonesia," City \& Society, Vol. 24, Issue 1 , hlm. 38-61.

Howell, J. (2008). "Modulations of Active Piety: Professors and Televangelists as Promoters of Indonesian Sufism". In G. Fealy \& S. White (eds.), Expressing Islam: Religious Life and Politics in Indonesia (pp. 63-85). Singapore: Institute of Southeast Asian Studies.

Ilham, Sholeh. 2011. "Kajian terhadap Tradisi Shalawat Jam'iyah Ahbabul Musthofa Kabupaten Kudus: Studi Living Hadits", Skripsi. Yogyakarta: Jurusan Tafsir dan Hadits, Fak. Ushuluddin, Studi Agama, dan Pemikiran Islam UIN Sunan Kalijaga Yogyakarta.

Kamaluddin, R. Tamtam. 2013. "Tradisi Membaca Syair Al-Barzanji di Lingkungan Sosiokultural Masyarakat Kabupaten Cianjur Provinsi Jawa Barat: Kajian Makna, Nilai-Nilai Pendidikan Akhlak, dan Upaya Pelestariannya", Tesis. Bandung: Universitas Pendidikan Indonesia.

Kitiarsa, P. (2008). "Toward A Sociology of Religious Commodification." Bryan S. Turner (ed.). Religious Commodification in Asia Marketing God. New York: Routledge.

Kitiarsa, P. (Ed.). (2008). Religious Commodification in Asia: Marketing Gods. London and New York: Routledge. DOI $\underline{10.4324 / 9780203937877}$

Laksono, P. M. (1985). Tradisi dalam Struktur Masyarakat Jawa Kerajaan dan Pedesaan: Alih Ubah Berpikir Orang Jawa. Yogyakarta: Gadjah Mada University Press. 
Munawaroh. (2007). "Tradisi Pembacaan Barzanji bagi Umat Islam." Jantra, (2)3, Juni, 177-183.

Muzakka, M. (2003). "Tradisi Lisan Pesantren dan Pemberdayaan Politik Kaum Santri: Kajian terhadap Tradisi Shalawatan." Makalah dipresentasikan dalam

Nef-Saluz, C. (2007). Islamic Pop Culture in Indonesia: An Anthropological Field Study on Vieling Practices among Students of Gadjah Mada University. Berlin: Institut for Sozialanthropoligie Universitat Bern.

Rasmussen, A. (2010). "Performing Piety through Islamic Musical Arts." Women, the Recited Qur'an, and Islamic Music in Indonesia. California: University of California Press.

Rosyid, N. (2008). "Pembentukan Hasrat Bershalawat Bersama Habib dalam Konteks Kapitalisme Lanjut di Indonesia." Skripsi. Yogyakarta: Jurusan Antropologi, Fak. Ilmu Budaya, Universitas Gadjah Mada Yogyakarta.

Safi'i, A. (2013). "Pembacaan Maulid Simt AdDurar dan Pengaruhnya terhadap Mahabbah kepada Rasulullah pada Jama'ah Jami'iyyah Maulid Simtuddurar Ahbabul Musthofa Kabupaten Kudus." Skripsi. Semarang: Jurusan Tasawuf dan Psikoterapi, Fakultas Ushuluddin, Institut Agama Islam Negeri Walisongo.

Sinaga, S. S. (2001). "Akulturasi Kesenian Rebana." Harmonia: Jurnal Pengetahuan dan Pemikiran Seni, 2(3), September-Desember, 72-83.

Sumbulah, U. (2012). "Islam Jawa dan Akulturasi Budaya: Karakteristik, Variasi, dan Ketaatan Ekspresif." e/Harakah, (14) 1, 12-27.

Susilantini, E. (2006). "Serat Dzikir Maulud: Kajian Aspek Keagamaan dan Tradisi
Masyarakat." Naskah belum diterbitkan. Yogyakarta: Balai Kajian Sejarah dan Nilai Tradisional Yogyakarta.

Wargadinata, W. (2008). "Tradisi Sastra Profetik dan Peningkatan Tradisi Keagamaan." Jurnal Ulul Albab, (September), 32-45.

Woodward, M. et. al. (2012). "Ordering What is Right, Forbidding What is Wrong: Two faces of Hadhrami Dakwah in Contemporary Indonesia". Review of Indonesian and Malaysian Affairs, 46(2), 105-146.

Zamhari, A. \& Howell, J.D. (2012). "Taking Sufism to the Streets: Majelis Zikir and Majelis Salawat as New Venues for Popular Islamic Piety in Indonesia". Review of Indonesian and Malaysian Affairs, 46(2), 47-75.

Zuhri, S. (2012). "Maulid Nabi, Bukti Cinta Rasul?" http.//asysyariah.com, 26 April. 